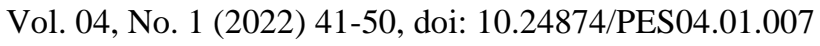 \\ Proceedings on Engineering Sciences
}

\section{THE INFLUENCE OF QUALITY MANAGEMENT AND ERP SYSTEMS ON ORGANISATIONAL CULTURE AND PERFORMANCE} Bongumusa Cebekhulu ${ }^{1}$
Paul Ozor
Received 15.11.2021.

Accepted 09.01.2022.

UDC - 005.71-027.233:[005.6+005.511:004.45]
Keywords:

Quality Management; Enterprise Resource Systems; Organisational Culture; Organisational Performance.

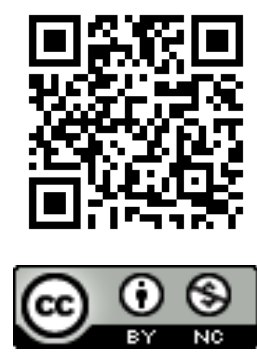

A B S T R A C T

Whereas quality management practices are important enterprise-level instruments for strategic management, enterprise resource planning systems (ERP) play a pivotal role in business process integration. The later presents potentialities for better information flows and improved control over company resources. The successful integration of QM practices and ERP system can offer a head-start in decision-making, planning, and execution to the organisations' performance. This research scrutinises the elements of $Q M$ practices and ERP systems and assesses the relationship between organisational culture and organisational performance. The research uses the case of twenty-one public sector organisations in South Africa. Structural Equation Modelling was utilised to examine the research hypotheses. The research revealed that the QMS practices have an indirect influence on organisational performance while ERP systems possesses both positive and direct effect on organisational performance.

(C) 2022 Published by Faculty of Engineering

\section{INTRODUCTION}

The competitiveness of the global business environment emphasises the need for organisations to heed the call of enhancing operational performance through the application of creative strategies and ideas that provide support to the business and ensures that competitive relevance in the market. To increase the focus on improved development processes, various organisations utilise different approaches, techniques, and philosophies, such as total quality management (TQM), and enterprise resource planning (ERP). Researchers describe Quality management (QM) as a management style and a set of guiding principles that are implemented and adopted by leaders in companies to enhance organisational performance and competitiveness. Quality Management is generally defined as a management philosophy that is associated with the control of the production and other processes to facilitate the provision of requisite product design and features in line with customers' expectations. This definition implores QM to prioritise a range of issues, including raw material sourcing activities, product development and design, final product delivery, as well as post sales service, in addition to the main characteristic of identifying continuous improvement opportunities to achieve excellence and accomplish sustainability and efficiency. Reed et al. (2000) observed that, under most quality management frameworks, it is apparent that firms can enhance their business processes, organisational 
performance, employees and customers' satisfaction, supplier relations and their reputation, through improving organisational quality culture. Even though quality management has been researched more, literature shows that there isstill a shortage of harmony and coherence in its concepts, descriptions, crucial elements, and the relationship between organisational performance and quality. The varied observations regarding the success of quality practices compels researchers to ponder on factors that contribute to QM success.

The implementation and application of ERP systems as an innovation tool in various sizes and types of organisations has been documented. Some organisations reported satisfaction with the benefits that ERP systems offer, and other organisations did not seem to extract any tangible benefits from the implementation. This points to the fact that ERP systems are very complicated systems and rely on other factors for organisations to realise and achieve the potential benefits that it can provide. Combining information systems and Quality Management Systems (QMS), such as TQM, can yield significant organisational impact. Information technology systems, like ERP, assist with conveying real time information and communication services and quality management systems (QMS) which are concerned with policies, principles, procedures, and processes necessary for achieving the quality objectives, are the mainstays of effective organisations. The development, design, and operation of these two important systems is usually uncoordinated, which results in inconsistencies, redundancy, and inefficiency. This specifies the need for integration or coordination of the two systems. Several other scholars also argue for the relationship between information technology (IT) and quality management. These studies conclude that IS and QMS are complimentary resources. Complementarity, in this case, denotes an improvement of resource value, and is observed when the output of one resource is greater when another resource is present than it is when that resource is alone. Against this backdrop, the aim of this research is to examine the nature of the relationships among QM practices, ERP systems, organisation culture and organisational performance.

The relationship between these variables is examined within the setting of the South African public sector. This study aims to contribute to the literature on the influence of QM and ERP systems on organisational performance. The implementation of both these systems is dependent on the culture found within organisations, and as such, this study assesses the effect of organisational culture as well. Several researchers have studied and identified relationships among QM practices and assessed the influence that these practices have on performance. Sila and Ebrahimpour (2005) concluded that there is a positive relationship between QM practices and organisational performance while (Nair, 2006) found that no relationship between $\mathrm{QM}$ practices and organisational performance. This might mean that different settings or environments yield different outcomes and it worth assessing this relationship under various settings and in the presence of other variables. There are also several texts that indicate the positive influence of organisational culture on QM practices. Organisational culture has been cited as one of the factors that determines whether TQM implementation will be a success or not. There have since been many other quality management techniques that are related to TQM but have slightly different dimensions. Based on the researcher's observations, research output and information on how the public organisations' culture drives the implementation of an effective QMS-ISO 9001, influencing the effectiveness of the organisations, is very limited. This study attempts to fill the gap in knowledge by using the setting of South Africa's stateowned entities to examine influence of organisational culture on QMS, ERP systems and organisational performance.

\section{LITERATURE REVIEW}

As a precursor to the study of the relationships between QM systems, ERP, organisational culture, and organisational performance, it is important to start by presenting available literature on the concepts to bring to the fore some of the research that has been conducted to assess these relationships.

\subsection{Quality Management Practices}

Talib et al. (2001) consider quality management as one of the most important apparatus of strategic management. It entails properly applying practices and principles of quality throughout the organisation. Measuring quality performance is critical to effectively managing an organisation. Therefore, it is crucial to assess how Quality Management is implemented to make it possible gauge the influence that QM practices have on the organisational performance. By pinpointing important aspects of quality management that positively impact quality improvement, Kaynak and Hartley (2008) evaluated the effect of QM practices on organisations. They concluded that process management, QM design, QM strategy, top management support and, education and training, were QM practices that had an impact on organisational performance.

Over the last two decades, research on QM has progressed and produced several empirical and theoretical studies that have measured and defined a group of important QM practices (Kaynak \& Hartley, 2008). These studies make it known that a significant relationship exists between key QM practices and organisational performance. That relationship also extends to the non-financial performance. QM practices have the potential to improve performance indicators associated with customers, and production performance. The growing competitiveness of the market will also lead to the QM practices becomingmore important, particularly the type that is concerned with the 
improvement of processes and overall effectiveness. Zeng et al. (2015) stated that the results from several studies dealing with the relationship between organisational performance and QM practices have indicated some ambiguity and inconsistency in the conclusions. These inconclusive outcomes may be better explained in individual research contexts and by using other methods of analysis. They conclude that more research is still required to further explore these relationships.

\subsection{Organisational Culture}

The culture that prevails in the context of the organisation is amongst the key elements for the successful implementation of QM practices. Many scholars have spent time put on a lot of effort on analysing this concept. Catanzaro et al. (2010) posit that the concept of culture can be found at various levels, such as national and organisational culture. The latter is generally described in literature as a set of beliefs, norms, and values that are common amongst people within an organisation. Organisational culture is a variable that sets one organisation apart from another. It isa wide-ranging concept leverages people within an organisation by transforming performance outcomes and behaviour, and the environment outside the organisation. In the context of this study, Prajogo and McDermont (2005) noticed the shift of focus in quality management research from concentrating on the more observable "hard" aspects, like techniques, tools, and systems to what is considered "softer" aspects like cultural and behavioural aspects which are more difficult to measure. It is said that a common challenge that is often encountered when culture and QMS are being discussed, is that there is an unclear boundary between quality management as a set of management practices and quality management as an organisational culture. Zeitz et al. (1997) however, distinguished organisational culture from QMS practices by stating that QMS practices are behavioural and organisational culture alludes to institutional interactions, attitudes, and beliefs. This study utilised this differentiation treated QM practices and organisational culture as separate variables.

\subsection{Organisational Performance}

Organisational performance is difficult to measure or define. Mudenyi et al. (2015) posit that the concept of organisational performance is frequent in literature, but the concept is difficult to describe because it has different connotations and there is no universally accepted description. The more common description of organisational performance is that it is the ability of an organisation to achieve its targets and objectives through efficacious utilisation of resources. Hefferman and Flood (2000) pointed out that organisational performance grapples with not only the definition problem but a conceptual problem as well. Performance is sometimes confused with productivity and many people struggle with differentiating between the two. Being a broad concept, organisational performance can even extend into productivity, quality, and consistency, and other factors. Though it may be difficult to define and measure organisational performance, factors that affect the performance of an organisation can be measured and the extent of that effect can also be measured and defined. Various scholars have, therefore, measured the effect of different factors on different dimensions of performance.

Djekic et al. (2014) illustrated that the implementation of quality management systems enables organisations to improve their financial and operational performance and to enhance product quality and increase sales, profit, and market share. Scholars have reached divided conclusions on relationship between QM and organisational performance, with Prajogo and McDermont (2005), concluding that there is a positive relationship between the two and Rich (2008) concluded that there was no link between QM programs and organisational performance. Sila and Ebrahimpour (2005) observed that some factors may not be associated with some performance measures in certain industries, countries, sectors, or type of organisation purely due to the fact that those factors do not apply to that context and are, therefore, not a good indicator or predictor of performance. The research recommended the exploration of these factors in different settings and contexts.

\subsection{ERP Systems}

One of the main purposes of ERP systems is to collate and integrate a broad range of information pertaining to organisational resources to develop cooperation with business partners, satisfy customer needs, and improve business performance. Al-Mashari et al. (2003) posit that ERP systems are solutions that are fused with the business processes and company's functions. ERP systems are a combination of software and hardware that facilitate the harmonisation and standardisation of business operations through the integration of data and information that is utilised throughout the organisation. ERP systems simplify the management of suppliers, production planning, accounting, human resources, distribution, sales, and customer services by merging them into one system and is better equipped to integrate the various divisions' data systems, enabling unrestricted information linking between customers, suppliers, and distributors.

The development of internet and its role in many aspects of everyday life has also meant that businesses have had to adapt their methods and find ways of exploiting the use of IT tools available to them. Many studies state that organisations implement ERP systems for a number of different reasons. Some of these reasons are tangible while other are intangible but what is clear is that ERP presents numerous advantages. Some of these advantages include normalisation of company processes, digitalisation of trading procedures, integration of 
information and facilities, reduced man hours/workforce, better flexibility, quicker decision-making, and information-based problem solving. Barata and Cunha (2017) recommended the integration of both systems for improved business performance, stating that each of the two systems have distinct functions and objectives but still depend on each other, and that there is a sizeable overlap in actions and concerns during the planning, implementation, and operation of both systems. Operating these systems require coordination, particularly when it comes to overseeing improvement and organisational change. Most of the literature reviewed show that very few studies on the effect of different factors on the organisational performance dimensions were performed in public organisations or in South Africa. Cebekhulu et al. (2020) posit that the successful incorporation of ERP systems into organisational structures result in a range of socio and technical challenges and that these challenges differ from one setting to the next. This assertion is also corroborated bySila and Ebrahimpour (2005), who highlighted the importance of different settings and areas to be explored, in more detail, when it comes to the relationship between ERP and organisational performance.

\section{RESEARCH HYPOTHESES AND CONCEPTUAL MODEL}

Figure 1 presents a conceptual framework, based Structural Equation Modelling (SEM) in SPSS. In the framework, latent variable consists of various constructs. Quality Management practices comprise of five constructs. These are top management support, supplier quality management, service design, quality data reporting, and customer relations. Each construct consists of measurement items.

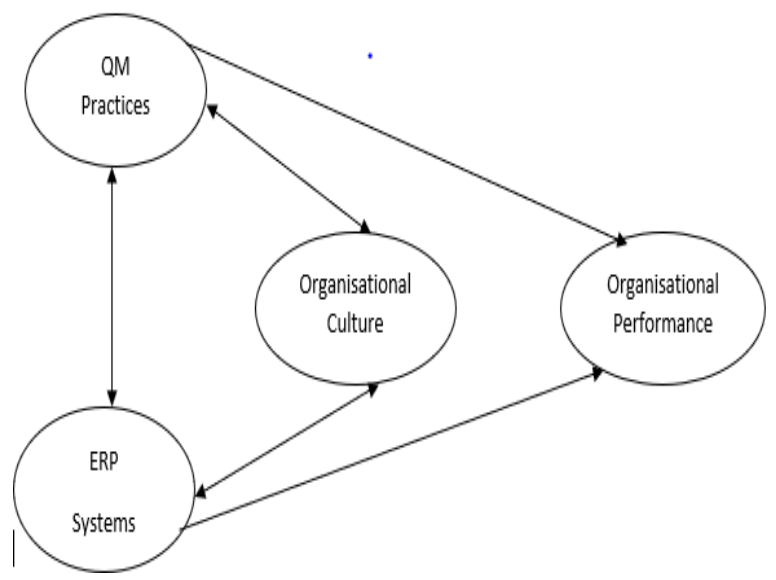

Figure 1. Path Diagram

Table 1 provides a summary of the variables, the constructs and associated measurement items. ERP system was conceptualised as a four-dimensional construct. These are organisational impact, individual impact, information quality, and systems quality. Organisational culture was conceptualised as a threedimensional construct. These are outcome orientation, teamwork, and stability. Lastly, organisational performance was operationalised as a two-dimensional construct, namely, satisfaction level and business results. All these dimensions were inductively developed, and literature support was again utilised in developing the expected relationships among constructs. In this study, ERP systems, QM practices, and organisational culture were considered as latent-independent (exogenous) variables, while organisational performance is utilised as latent-dependent (endogenous) variable. From this conceptual model, a number of hypotheses were developed.

The framework proposes that ERP have an impact on organisational culture and organisational performance. In addition, QMS practices effect the ERP systems and have an influence on organisational culture and organisational performance. The pivotal role of an organisational culture that is receptive to change and conducive to QMS programs has been mentioned on several occasions in literature (Prajogo \& McDermott, 2005), with various authors recommending that there must be changes in workforce attitudes and organisational culture for QMS to be effective. Altering the values of any company is not a simple endeavour as those values are usually firmly rooted in the company's culture. As such, several scholars are of the view that the implementation of QMS brings about a transformation in the organisation's culture. The aforementioned arguments result in the following hypothesis:

\section{H1: QM practices have an influence on organisational culture.}

Various studies researching ERP systems argue that ERP directly influences an organisation's performance. Hunton et al. (2003) assessed the effect of adopting ERP systems on organisational performance. This was done by a comparison of companies that use ERP systems against companies that do not use ERP systems. The conclusion reached was that significant improvement in turnover and on return on investment (ROI) was observed from the ERP system users. These results, however, differ as the size of the organisation changes. This study proposes that there is a positive relationship between ERP systems and organisational performance.

\section{H2: ERP systems have a positive influence on} organisational performance.

Adopting quality management can improve the enterprise's organisational performance. Research by Djekic et al. (2014) shows that the implementation of quality management systems enables companies to achieve improved financial and operational performance, enhancing the quality of services/products and growth in profit, sales, and market share. Based on the above assertions, the following hypothesis is framed: 
Table 1. Summary of constructs and variables

\begin{tabular}{|c|c|c|c|c|}
\hline Variables & Constructs & Description & $\begin{array}{l}\text { No.of } \\
\text { Items }\end{array}$ & Code \\
\hline \multirow[t]{5}{*}{ QM Practices } & Top Management Support & $\begin{array}{l}\text { Provision of resources, leadership and enabling } \\
\text { conditions for quality }\end{array}$ & 5 & QMS1 \\
\hline & Service Design & Based on customers' requirements & 4 & QMS2 \\
\hline & $\begin{array}{l}\text { Supplier quality } \\
\text { management }\end{array}$ & $\begin{array}{l}\text { Quality over price and collaborative problem-solving } \\
\text { techniques }\end{array}$ & 4 & QMS3 \\
\hline & $\begin{array}{l}\text { Quality Data } \\
\text { Reporting }\end{array}$ & $\begin{array}{l}\text { Records about cost of quality, other indicators are kept } \\
\text { for analysis }\end{array}$ & 4 & QMS4 \\
\hline & Customer Relations & Best-in-class customer satisfactionis emphasized & 3 & QMS5 \\
\hline \multirow[t]{4}{*}{ ERP } & Organisational Impact & Influence of the system on the organisation & 4 & ERP1 \\
\hline & Individual Impact & $\begin{array}{l}\text { Influence of the system on the individuals and how } \\
\text { tasks are performed }\end{array}$ & 4 & ERP2 \\
\hline & Information Quality & $\begin{array}{l}\text { Data and information on processes and performance } \\
\text { are readily available and of usable quality }\end{array}$ & 4 & ERP3 \\
\hline & Systems Quality & $\begin{array}{l}\text { Fitness for use and able to be integrated to legacy } \\
\text { systems }\end{array}$ & 4 & ERP4 \\
\hline \multirow[t]{3}{*}{$\begin{array}{c}\text { Organisational } \\
\text { Culture }\end{array}$} & Outcome Orientation & The organisation being results-driven & 3 & OC1 \\
\hline & Teamwork & $\begin{array}{l}\text { Collaborating with other people and other } \\
\text { departments, being team oriented and socially } \\
\text { responsible }\end{array}$ & 5 & $\mathrm{OC} 2$ \\
\hline & Stability & Low staff turn-over and financially stable & 2 & OC3 \\
\hline \multirow[t]{2}{*}{$\begin{array}{l}\text { Organisational } \\
\text { Performance }\end{array}$} & Satisfaction Level & $\begin{array}{l}\text { Customers are satisfied with the services and } \\
\text { employees are happy to be working in the organisation }\end{array}$ & 2 & OP1 \\
\hline & Business Results & $\begin{array}{l}\text { Performance of the quality system, improved } \\
\text { productivity, and cost performance }\end{array}$ & 4 & OP2 \\
\hline
\end{tabular}

\section{H3: QM practices positively affect organisational performance.}

Hartman et al. (2002) stated that when IS design adopts QMS, it can meet potential expectations and combine both the technical and behavioural aspects. This confirms the complementarity of the two systems, because the aforementioned research illustrates that when QMS maturity increases, the diffusion of ERP becomes more participative, and user centred.

\section{H4: QMS practices have a positive influence on ERP systems.}

Ifinedo et al. (2010) studied the effects of organisational culture on ERP systems effectiveness and/or success and emphasised the importance of organisational culture on ERP adoption, stating that, ERP naturally imposes logic on the company's strategy and culture. There is, therefore, a considerable amount of evidence that suggests that ERP systems alter intra-company functioning and organisational culture. The overall success of ERP is enhanced when the fundamental rationale of the system and the prevailing culture within the adopting enterprise are harmonious.

\section{H5: ERP systems influence organisational culture.}

Yesil and Kaya (2012) posit that the research on organisational culture constantly strengthens the assertion that organisational culture is required for effective performance and operation of companies. There have been arguments that advocate for the idea that organisational culture is associated with long-term effectiveness and organisational performance. Despite questions being raised around the link between culture and performance, there seems to be enough evidence for the proposed relationship between organisational performance and organisational culture.

\section{H6: Organisational culture has a positive influence on organisational performance.}

The study then utilised SEM, a multivariate statistical technique, to empirically examine the hypotheses.

\section{EMPIRICAL ASSESSMENT}

This research was conducted to examine the relationships among QM practices, ERP systems, organisational culture, and organisational performance. The methodology started by developing the constructs' domain using a literature review and proceeded with the identification of the different items that will be used to measure those constructs that form the research model. The initial pool of items was utilised to create the initial questionnaire that was used as a pilot study to purify the measures before a final questionnaire was created and implemented in the main study. The data was collected through a survey, which is outlined in the next sections.

\subsection{Construct Development, Sampling and Measures}

To test the hypotheses stated in section three above, this study used multi-item scales adopted from previous research. QMS practices had five constructs. These 
constructs were adopted from Lin et al. (2005). ERP systems' four constructs were adopted from DeLone and McLean (2004). Organisational culture also had four constructs which were adopted from Baird et al. (2011). The two constructs used to measure organisational performance were adopted from Lin et al. (2005). A survey was used to validate the hypothesised relationships and to establish a well-grounded discussion coexisting with the observed findings.

All of the items were measured using a 5-point Likert Scale, where one indicated "strongly disagree" and five indicated "strongly agree". The respondents for the study were extracted from public sector organisations in South Africa. To narrow down the sample, this study utilised the report by Fuzile (2015) which stated that ERP systems are generally found in Schedule Two Public Entities in South Africa. Using the list of Schedule 2 public entities, employees from twenty-one public entities were requested to participate. To get a representative sample, employees in different roles, with varying qualifications were sent the survey. Of the 378 employees contacted, 162 potential respondents agreed to participate in the survey but only 117 returned usable questionnaires. The other questionnaires were deleted for being incomplete. A response rate of $30,95 \%$ was achieved.

\subsection{Validity and Reliability}

Following the completion of the data collection, reliability and validity of the measures were assessed by subjecting them to a data purification process. Reliability was tested by calculating Cronbach's Alpha coefficient. The generally accepted classification of Cronbach's alpha coefficients is that coefficients between 0.70 and 0.90 indicate high reliability and coefficients that fall between 0.50 and 0.70 indicate moderate reliability. Composite reliability, which considers actual factor loadings as opposed to assuming equal loadings for all items, was also calculated. The composite reliability values calculated were higher than 0.60 (Fornell \& Larcker, 1981). This confirmed that the measures used were reliable. The results of the factor loadings and Cronbach's Alpha values are presented in Table 2.

Table 2. Results of the factor loadings and Cronbach's Alpha values

\begin{tabular}{|c|c|c|c|}
\hline Variables & Constructs & Cronbach's $\boldsymbol{\alpha}$ & Loading Range \\
\hline \multirow{4}{*}{ QM Practices } & Top Management Support & .804 & $.442-.851$ \\
\hline & Service Design & .817 & $.772-.837$ \\
\cline { 2 - 4 } & Supplier quality management & .878 & $.833-.883$ \\
\cline { 2 - 4 } & Quality Data Reporting & .703 & $.651-.799$ \\
\cline { 2 - 4 } & Customer Relations & .749 & $.390-.880$ \\
\hline \multirow{2}{*}{ ERP } & Organisational Impact & .755 & $.728-.822$ \\
\hline & Individual Impact & .743 & $.426-.802$ \\
\cline { 2 - 4 } & Information Quality & .647 & $.457-.855$ \\
\hline & Systems Quality & .639 & $.446-.896$ \\
\hline Organisational Culture & Outcome Orientation & .621 & $.497-.737$ \\
\hline & Teamwork & .585 & .946 \\
\hline
\end{tabular}

As can be observed from Table 2, Cronbach's alpha values of all the research constructs fall within the $0.5-0.9$ range, demonstrating moderate to high reliability. Stringent thresholds for factor loadings were used. The rule of thumb when it comes to factor loadings is that: loadings of 0.32 are poor,loadings from 0.45 are fair, loadings from 0.55 are good and loadings from 0.63 very good and excellent. Using this recommendation, the validity of the constructs was confirmed as all factor loadings were above 0.32 . The mean of each multivariate construct was then taken and used for the rest of the analysis process.

Convergent validity was ascertained by calculating Average Variance Extracted (AVE) in Microsoft Excel. Fornell and Larcker (1981) state that the AVE of above 0.5 is acceptable. The AVE's calculated in this study ranged between 0.521 and 0.929 , which confirmed convergent validity of the research items. Discriminant validity is established when the square root of the AVE for each latent variable is higher than the correlations among the latent variables. Using Microsoft Excel, the square root of the AVE was calculated and found to be greater than correlations among the latent variables.

\subsection{Hypotheses Testing}

To test the conceptual model, Analysis of Moment Structures (Amos) was used. Barnidge and Zuniga (2017) define Amos as an IBM SPSS Statistics module that was developed to analyse covariance structure models, including path analysis, structural equation modelling (SEM), and confirmatory factor analysis (CFA). This study analysed both the measurement and structural models to ensure that the results were acceptable and that the results were consistent with the fundamental theory. The SEM model is presented in Figure 2 while Table 3 summarises the hypotheses, path coefficients, and whether the hypotheses was supported or not. 


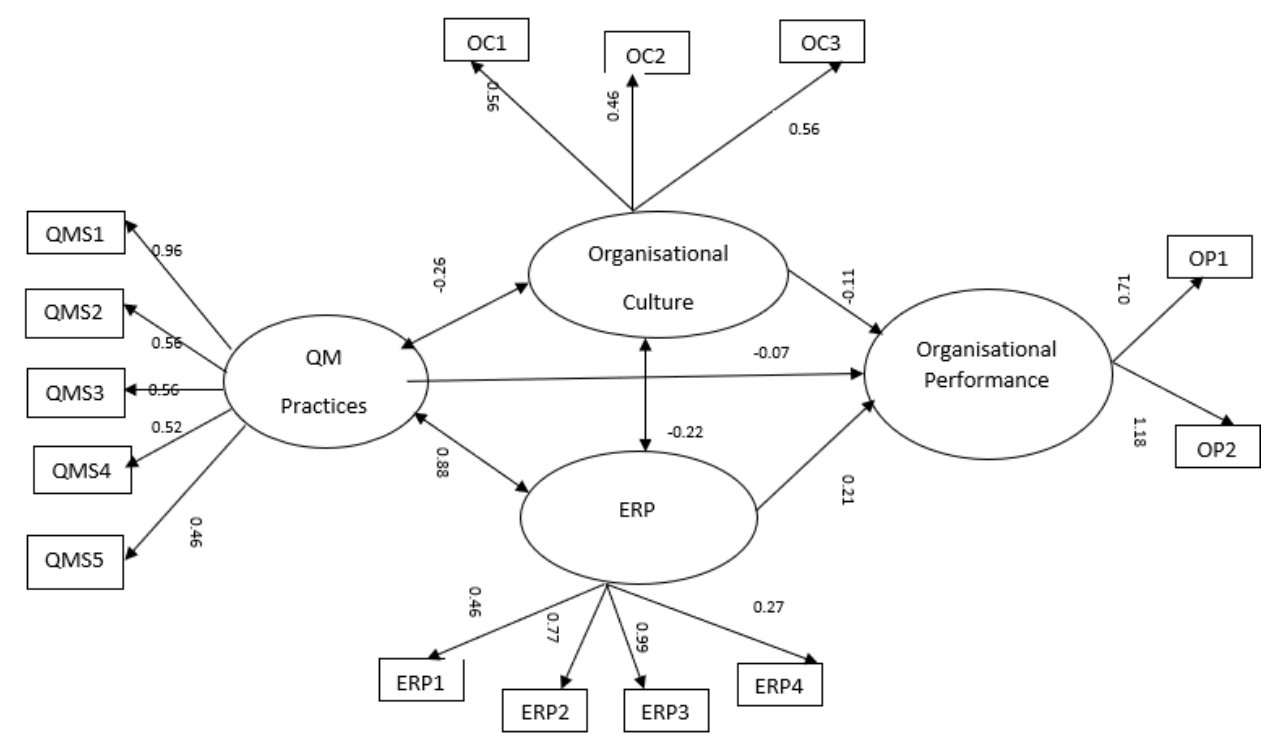

Figure 2. The SEM model

Tan (2001) posit that the measurement model is concerned with the validity and reliability of the constructs in measuring the latent variables, whereas the structural model deals with the relations, direct and indirect, among the latent variables. This made the SEM technique to be considered suitable for this research. To evaluate the paths, this study analysed the path coefficients. As a rule of thumb, the standardised path coefficients with absolute values of less than 0,10 are said to indicate a small effect, those with values around 0.30 , indicate moderate effect and those with values of 0,50 and above, indicate a significant effect. The effect of QM practices on ERP systems was found to be significant $(\beta=0.88)$, as illustrated in figure 2. This is in support of the notion that QM practices and ERP systems influence each other and should be implemented concurrently.

Table 3. Summary of the structural model results

\begin{tabular}{|c|c|c|c|}
\hline Path & Hypothesis & $\begin{array}{c}\text { Path } \\
\text { Coefficients }\end{array}$ & Decision \\
\hline QM > OC & H1 & -0.26 & $\begin{array}{c}\text { Not } \\
\text { Supported }\end{array}$ \\
\hline ERP> OP & H2 & 0.21 & Supported \\
\hline QM > OP & H3 & 0.07 & $\begin{array}{c}\text { Not } \\
\text { Supported }\end{array}$ \\
\hline QM>ERP & H4 & 0.88 & Supported \\
\hline ERP > OC & H5 & -0.22 & $\begin{array}{c}\text { Not } \\
\text { Supported }\end{array}$ \\
\hline OC> OP & H6 & -0.11 & $\begin{array}{c}\text { Not } \\
\text { Supported }\end{array}$ \\
\hline
\end{tabular}

Relationships among QM practices, ERP systems, organisational culture and organisational performance are also demonstrated. As can be observed from the model, QM practices $(\beta=-0.26)$ affect organisational culture, which is the inverse of H1. QM practices have a very small or insignificant influence on organisational performance $(\beta=0.07)$. With regards to ERP systems, the observation is that ERP systems have a moderate effect on organisational culture $(\beta=0.22)$, this does not support $H 4$, as the value is negative. ERP systems, however, were proved to have moderate influence on organisational performance $(\beta=$ 0.21 ), therefore H5 is supported. Lastly, the study found that organisational culture has a small, inverse influence organisational performance $(\beta=-0.11)$, which means that H6 is not supported.

The quality of the SEM analysis was then assessed, and the results show that most of the measurements possess significant loadings to their corresponding second order constructs. The model fit indices computed were root mean square error of approximation (RMSEA) $=0,068$, comparative fit index $(\mathrm{CFI})=0,961$, Tusker-Lewis Index $(\mathrm{TLI})=0,943$ and the standardised $\mathrm{RMR}=0,071$. Based on these results, the model was deemed acceptable.

\section{DISCUSSION OF RESULTS.}

Several observations are evident from the study. The proposed hypothesis, $\mathrm{H} 2$, is not supported. The data shows that QM practices have moderate influence on organisational performance. Demirbag et al. (2006) also reported a similar finding from their research and stated that the relationship between QM practices and organisational performance can be enhanced using nonfinancial performance measures as a mediating factor. Other scholars observed that QM practices have an indirect influence on organisational performance. That study examined two paths that contributed to the indirect influence, to quantify that indirect influence. This study utilised the same method. In this study, organisational culture is the mediator for the first path whereas ERP systems and organisational culture are the mediators for the second path. Therefore, the indirect effect of QM practices on organisational performance is 0,115 (that is $0.34 \times 0.19+0.91+0.29 \times 0.19)$. Interviews with public sector experts about this study's findings revealed that QMS in South Africa's public sector is used mostly as a management concept and not as an apparatus for 
performance improvement. This also supports that assertion that QMS do not provide quick fixes but require long term commitment to maximise the benefits.

Secondly, this study's data confirms $\mathrm{H} 2$ and concludes that ERP systems have a moderate, direct influence on organisational performance. This finding is contrary to Weider et al. (2006) who found that there was an absence of any impact on organisational performance from ERP systems. However, Dehning and Richardson, (2002) provided a possible explanation for the absence of impact, stating that in the short run, the implementation costs of ERPS usually over exceed the short to medium term business performance. ERP systems' influence on organisational performance is, therefore, only notable when the system matures. The maturity of the systems plays an important role in determining the impact of ERP systems on organisational performance. Other researchers write of the mediating and moderating effects of QMS and organisational excellence, respectively, on the relationship between ERP systems and organisational performance. This study's data supports the claim that QMS is a mediator for ERP and organisational performance. The results show that the indirect influence of ERP systems on organisational performance is 0,185 $(0,88 \times 0,21)$. This result is expected as ERP and QMS systems, in South Africa's public sector, have not reached maturity yet. Slow levels of ERP adaptation levels within the public sector in South Africa have been observed. It is possible that the organisations have not realised the benefits of ERP system implementation which may also explain the results obtained for $\mathrm{H} 2$.

\section{CONCLUSION}

This paper has empirically tested a framework identifying the relationships among QM practices, ERP systems, organisational culture, and organisational performance. The elementary goal of this research was to investigate the influence of QM practices and ERP systems on organisational culture and organisational performance. There is an inconsistency in the literature with regards to the influence of QM Systems on organisational performance and several scholars have tried to explain this association better by integrating the influence of different variables into the setting. This study attempted to contribute to the resolution of this inconsistency through the introduction ERP systems and organisational culture, as the additional variable, to explain how QM systems may affect organisational performance. The hypotheses were tested using Amos 27 . The results show that most of the hypotheses were not supported but the presence of mediating factors prove indirect influence.

These findings partially support the conceptual model and provide several managerial implications. Firstly, this study provides an apparatus that can be practically utilised by managers to assess the ERP systems and QM practices, through the implementation and validation of these systems. Secondly, the effectiveness of QM practices and ERP systems in increasing the performance were proven. The implementation of both systems requires patience and proper planning as the benefits of both systems can only be realised in the long term. Thirdly, Quality Management practices continue to play a pivotal role in the relationship between ERP systems and organisational performance. It is worth noting though that QM practices and ERP systems are heavily affected by contextual factors, like organisation size, sector, or industry type, etc. This study integrated the activities of the QM and ERP systems and correlated those activities with organisational culture and organisational performance.

\section{References:}

Al-Mashari, M., Al-Mudimigh, A., \& Zairi, M. (2003). Enterprise resource planning: A taxonomy of critical factors. European journal of operational research, 146(2), 352-364

Baird, K., Hu, K. J., \& Reeve, R. (2011). The relationships between organizational culture, total quality management practices and operational performance. International Journal of Operations \& Production Management.

Barata, J., \& Cunha, P. R. (2017). Synergies between quality management and information systems: a literature review and map for further research. Total Quality Management \& Business Excellence, 28(3-4), 282-295.

Barnidge, M., \& De Zúñiga, H. G. (2017). Amos (software). The International Encyclopedia of Communication Research Methods, 1-3.

Catanzaro, D., Moore, H., \& Marshall, T. R. (2010). The impact of organizational culture on attraction and recruitment of job applicants. Journal of business and psychology, 25(4), 649-662.

Cebekhulu, B. M. B., Ozor, P. A., \&Mbohwa, C. (2020). Implementation of a cloud-based ERP system in a public entity.In Proceedings of the International Symposium on Industrial Engineering and Operations Management (IEOM). Harare (pp. 410-416).

DeLone, W. H., \& McLean, E. R. (2004). Measuring e-commerce success: Applying the DeLone\& McLean information systems success model. International Journal of electronic commerce, 9(1), 31-47.

Dehning, B., \& Richardson, V. J. (2002). Returns on investments in information technology: A research synthesis. Journal of information systems, 16(1), 7-30. 
Demirbag, M., Tatoglu, E., Tekinkus, M. \& Zaim, S. (2006). An analysis of the relationship between TQM implementation and organizational performance: evidence from Turkish SMEs. Journal of manufacturing technology management.

Djekic, I., Tomic, N., Smigic, N., Tomasevic, I., Radovanovic, R., \& Rajkovic, A. (2014). Quality management effects in certified Serbian companies producing food of animal origin. Total Quality Management \& Business Excellence, 25(3-4), 383-396.

Fornell, C., \& Larcker, D. F. (1981). Evaluating structural equation models with unobservable variables and measurement error. Journal of marketing research, 18(1), 39-50.

Fuzile, L. (2015). Public sector supply chain management review. Department of National Treasury Republic of South Africa, 4-8.

Hartman, S. J., Fok, L. Y., Fok, W. M., \& Li, J. (2002). Relationships among quality management, IS use and organizational performance in the health care and non-health care setting. Total Quality Management, 13(7), 927-943.

Heffernan, M. M., \& Flood, P. C. (2000). An exploration of the relationships between the adoption of managerial competencies, organisational characteristics, human resource sophistication and performance in Irish organisations. Journal of European Industrial Training.

Hunton, J. E., Lippincott, B., \& Reck, J. L. (2003). Enterprise resource planning systems: comparing firm performance of adopters and nonadopters. International Journal of Accounting information systems, 4(3), 165-184.

Ifinedo, P., Udo, G., \& Ifinedo, A. (2010). Organisational culture and IT resources impacts on ERP system success: an empirical investigation. International Journal of Business and Systems Research, 4(2),131-148.

Kaynak, H., \& Hartley, J. L. (2008). A replication and extension of quality management into the supply chain. Journal of Operations Management, 26(4), 468-489.

Lin, C., Chow, W. S., Madu, C. N., Kuei, C. H., \& Yu, P. P. (2005). A structural equation model of supply chain quality management and organizational performance. International journal of production economics, 96(3), 355-365.

Muduenyi, S., Oke, A. O., \& Fadenyi, O. (2015). Impact of organizational structure on organization performance. In International Conference on African development issues (CU-ICADI) 2015: Social and economic models for development Track (pp. 354-356).

Nair, A. (2006). Meta-analysis of the relationship between quality management practices and firm performance implications for quality management theory development. Journal of operations management, 24(6), 948-975.

Prajogo, D. I., \& McDermott, C. M. (2005). The relationship between total quality management practices and organizational culture. International Journal of Operations \& Production Management.

Rahman, S. U., \& Sohal, A. S. (2002). A review and classification of total quality management research in Australia and an agenda for future research. International Journal of Quality \& Reliability Management.

Reed, R., Lemak, D. J., \& Mero, N. P. (2000). Total quality management and sustainable competitive advantage. Journal of quality management, 5(1), 5-26.

Rich, E. (2008). Management fads and information delays: An exploratory simulation study. Journal of Business Research, 61(11), 1143-1151.

Sila, I., \& Ebrahimpour, M. (2005). Critical linkages among TQM factors and business results. International journal of operations \& production management.

Talib, F., Rahman, Z., \& Qureshi, M. N. (2010). The relationship between total quality management and quality performance in the service industry: a theoretical model. International Journal of Business, Management and Social Sciences (IJBMSS)MultiCraft, 1(1), 113-128.

Tan, K. C. (2001). A structural equation model of new product design and development. Decision Sciences, 32(2), 195226.

Yesil, S., \& Kaya, A. (2013). The effect of organizational culture on firm financial performance: Evidence from a developing country. Procedia-Social and Behavioral Sciences, 81, 428-437.

Zeitz, G., Johannesson, R., \& Ritchie Jr, J. E. (1997). An employee survey measuring total quality management practices and culture: Development and validation. Group \& Organization Management, 22(4), 414-444.

Zeng, J., Phan, C. A., \& Matsui, Y. (2015). The impact of hard and soft quality management on quality and innovation performance: An empirical study. International journal of production economics, 162, 216-226. 
Bongumusa Cebekhulu

University of Johannesburg,

Johannesburg,

South Africa

musa.ceb@gmail.com

\section{Dr Paul Ozor}

Department of Quality and Operations

Management,

University of Johannesburg,

South Africa

pozor@uj.ac.za

Department of Mechanical Engineering,

University of Nigeria Nsukka,

Nigeria

paul.ozor@unn.edu.ng 